\title{
A Conceptual Paper on Innovativeness of Academic Staff
}

\author{
John Baptist Hab'Imana* Jude Ssempebwa \\ College of Education and External Studies, Makerere University, P.O. Box 7062 Kampala- Uganda.
}

\begin{abstract}
The research is financed by Hab'Imana John Baptist
Abstract

This paper is a conceptual discussion of the construct of employee innovativeness isolating its antecedents in an organizational context. It arose as part of a study on the innovativeness of academic staff in universities in Uganda. The paper proposes a framework for studying employee innovativeness, and 3 hypotheses for future research basing on a review of recent literature. The main purpose of this paper is to demonstrate how organizational culture can facilitate innovativeness of academic staff. Thus, the paper contributes to the disclosure of different organizational culture dimensions that are relevant for innovativeness of academic staff in Higher Education Institutions (HEIs).
\end{abstract}

Keywords: Innovativeness, Academic Staff, Organizational culture, Academic staff, Higher education.

DOI: $10.7176 / \mathrm{JEP} / 11-18-06$

Publication date:June 30th 2020

\subsection{Introduction}

Employee Innovativeness is essential for organizations to survive and develop amidst the uncertainty and competitiveness of knowledge-based economies (Yuan \& Woodman, 2010). Thus, administrators at HEIs are expected to provide an environment where employees' work is appreciated and respected; involve their opinion in the decisions at higher levels; and offer an optimal level of autonomy and discretion (Heslin, 2010). Some of the key contextual factors that influence employee innovativeness are organizational culture and leadership. Thus, employee innovativeness can be supported by leaders through nurturing a conducive organizational culture. However, increasing globalization, fierce competition and the pace of technological change has tended to hinder leaders' efforts to create the needed work environment for the employees' innovativeness (Muceldili, Turaran and Erdil, 2013). Trot (2012) argued that innovativeness is reflected in individual's defined problems, having ideas and performing creative linkages and associations that culminate into inventions and innovations within organizations. In addition, individuals in the role of managers decide what activities should be undertaken, the amount of resources to be deployed and how they should be carried out. This calls for university managers to strengthen organizational culture that support individual initiatives that culminate into employee innovativeness.

Whereas employee innovativeness has been defined as engagement in innovative behaviors, which include behaviors related to the innovation process, i.e. opportunity exploration, idea generation, idea promotion and idea realization, with the aim of producing innovations ( Scott \& Bruce 1994, Ramamoorthy, Flood, Slattery \& Sardessai 2005, Parzefall et al, 2008), the most comprehensive of those definitions is that of Jereon- De Jong et al, (2007) who conceptualized employee innovativeness as the generation and implementation of significant new ideas, products, processes which are not assigned to task. They further distinguished four dimensions of employee innovativeness as reflected in Innovative Work Behavior (IWB), and labelled them as; Opportunity Exploration, Idea Generation, Idea Championing, and Idea Implementation. Opportunity Exploration dimension denotes ways to improve products, processes and services and looking for ways to improve them. Idea Generation refers to searching out new methods and solutions to identified problems. Idea Championing refers to finding support and building coalition by encouraging new organization members to be enthusiastic of new innovative ideas. Idea Implementation means systematic introduction of new ideas into work processes. Thus, it can be hypothesed from the above conceptualization that employee innovativeness is engaging in innovative work behavior of; opportunity exploration, idea generation, idea championing and idea implementation/ application. The concept of employee innovativeness is also related to internal characteristics of HEIs, such as organizational culture, strategies and structure (Hasanefendic, Birkholz, Horta, and van der Sijde, 2017). Although some studies consider alongside several drivers of innovativeness and acknowledge the importance of using broad approach to study key drivers of innovation in HEIs (e.g. Serdyukov, 2017) they have not considered organizational culture to deal with innovativeness of academic staff in Universities in Sub Saharan Africa (SSA).

\section{Theoretical review}

Hofstede's theory of Organizational Culture is the basis of this paper. The study of organizational culture, in depth, began with the work of Hofstede with his landmark study of IBM (Hofstede 1980). Hofstede himself provides two equivocal definitions of organizational culture; as "A collective programming of the mind which distinguishes one group from another" (Hofstede 2010), and as "Mental programming, patterns of thinking and 
feeling and potential acting" (Hofstede 1991, 1994). The purpose of organizational culture is to improve solidarity and cohesion, and to arouse employees' enthusiasm and creativity to improve the organization's economic efficiency. In addition, organizational culture greatly influences employee behavior (LI, 2015). This paper is based on Hofstede's three dimensions of organizational culture that has the greatest influence on employee innovativeness, namely; Uncertainty Acceptance, Power Distance and Collectivism.

This paper is based on review of literature on organizational culture as predictor of innovativeness of academic staff.

\subsection{Uncertainty Acceptance as determinant of employee innovativeness ( IWB)}

In the cross-national study Uncertainty Acceptance (UA) deals with the extent to which a social system rejects unstructured and ambiguous situations (Hofstede, Neuijen, Ohayv and Sanders, 1990). It measures employees' attempts to deal with uncertainty and ambiguity through tolerance and keeping stress levels low (Nana, 2013). Nana explained that UA is the extent to which the members of a culture feel threatened by ambiguous or unknown situations and have created beliefs and institutions that try to avoid these. Uncertainty avoidance within an organization is reflected in formal laws and informal rules controlling the rights and duties of superiors and employees, and additional, internal regulations controlling the work process (Hofstede, et al., 2010). According to Hofstede, Uncertainty Acceptance measures employees' attempts to deal with uncertainty and ambiguity through tolerance and keeping stress levels low. In uncertainty acceptance culture, people are threatened by lack of structure or by uncertain events. It determines the way people will deal with the future- such as having inherent control of events that are beyond their control (fatalism). People with high uncertainty acceptance culture will require structure and order with clear rules and guidance while people in low uncertainty acceptance are reluctant to make decisions and will require very structured work routines. Hofstede assumed that an academic staff working in an environment where uncertainty is accepted experiences low stress, feels at ease and executes his responsibilities with low anxiety. Such academic staff tolerates ambiguities of new ideas. Such a culture plays a great role in determining intention to innovate due to lower stress, collaborative and tolerance of deviant behavior.

\subsection{Power Distance as determinant of IWB (innovativeness of academic staff).}

According to Hofstede (2010), power distance measures how the relationships between superior and subordinate are detached. Power distance deals with the acceptance of inequality among ranks in the system (Omerzel, 2016 ). A high power distance refers to command chains as opposed to low power distance which emphasizes egalitarianism, where a worker can approach her boss and vice versa. A low score of power distance means that employees have equal rights, are collaborative and consultative.

Employee innovativeness which leads to new products, services, or processes, relies heavily on a continuous information flow between internal and external stakeholders in an organization. However, due to power distance and their hierarchical decision-making processes, organizations that are characterized by a hierarchical culture and centralized communication structures typically hinder interaction on a horizontal level (Song and Thieme, 2006).This leads to a reduced exchange of information. Furthermore, such an inefficient communication process with "powerless" members at lower hierarchical levels might also have a negative effect on employees' motivation to engage in innovative activities that are essential for new product development (Engelen, 2010). Such high power distance culture is unfavorable to innovativeness of academic staff.

Lans, Biemans and Baggen (2015), argued that in a bid to support employee innovativeness, policy could promote job complexity by designing jobs that challenge employees to learn, innovate and create exciting jobs. Furthermore, Lans et al (2015) argued that organizations such as HEIs should facilitate the learning, formally and informally thus reducing power distance for their employees. Conclusively, this suggests that work characteristics, job control and job demand are essential in the context of learning and employee innovativeness.

Power distance is the measure of inequality among people. This implies that a society's measure of inequality might be approved by both leaders and followers (Wei et al., 2008, Bankole, 2017). The power of knowledge is enhanced when knowledge is shared to bring innovative ideas, products and processes (Nonaka \& Takeuchi, 1995), and new programs (Hislop, 2013). Academics being one of the pillars of HEIs, where knowledge is created and shared, they are expected to promote academics' knowledge sharing in a low power distance culture. However, the actual behavior of academics might remain inhibited by numerous issues, namely; the organizational cultural elements such as power distance (Osama, Al-Kurdia, Ramzi El-Haddadehb and Tillal, 2020 ).

\subsection{Individualism/Collectivism and innovativeness of academic staff.}

Individualism/ collectivism is the third dimension discussed by Hofstede. In this dimension, differences between organization interest and self- interest are adequately matched. Hofstede (2010), indicated that in collective cultures, the interest of a group or organization is valued more than the interest of an individual. In contrast, in an 
individualist society, an individual's interests are valued over the interests of a group. Hofstede also observed that society's expectations in terms of individualism or collectivism are reflected by employees in the organizations. Collectivism dimension measures the degree of integration of employees, manifested through; harmony, in-group opinion and shared feeling of achievement of the organization. It also measures whether people prefer to work alone or in groups. It indicates the degree of social/community integration. For instance, USA has low power distance that facilitates singular individualistic achievements while in Guatemala social integration is ranked the highest (Omersel, 2016). They work together in groups, achieving collective performance as a group. Academic staff working in Collectivism subculture are empowered to be innovative by an overwhelming a sense of belonging, in-group opinion and a shared feeling of success.

These three organizational culture dimensions together constitute the basic values supporting employee innovativeness. Hofstede postulates that if all the three organizational cultural dimensions are positive, academic staff innovativeness would be enhanced. Alkailani and Kumar (2016) noted that vulnerability has a role to play in interpersonal influence on the innovative behavior of individuals. This is crucial in furnishing administrators and managers with useful information for training and facilitating innovativeness. Alkialani and Kumar further noted that higher susceptibility to interpersonal influences causes people to avoid individualism and adopt collectivism- moves of the crowd, staying with traditions, and tendency to go with the status quo.

\section{Conceptualization of Employee Innovativeness}

Over the years, due to a conceptual evolution, the concept of employee innovativeness and other similar terms have been used interchangeably. The term employee innovativeness is relatively new in the discourse of innovation and was first coined by Rogers (1995) as the degree to which an individual is relatively earlier in adopting new ideas than other members in a system. Contrary to this view, De Jong, (2007 ), Parzefall, et.al, (2008) and Vincent(2017) conceptualized employee innovativeness as the generation and implementation of significant new ideas, products, processes which are not assigned to task. Jereon- De Jong et al (2007) further distinguished four dimensions of Innovative Work Behavior (IWB), and label them as; opportunity exploration, idea generation, idea championing, and idea implementation. Earlier, Farr and Ford (1990) had defined IWB as an individual's behavior that aims to achieve the initiation and intentional introduction (within a work role, group or organization) of new and useful ideas, processes, products or procedures. Whereas previous scholars operationalized innovativeness with one dimensional measure with limited items De Jong and den Hartog (2007), and Vincent et al (2017) operationalized employ innovativeness as a multi-dimensional construct. In this paper, academic staff innovativeness is operationalized as engaging in innovative work behavior of opportunity exploration, idea generation, idea championing and idea implementation/application.

Academic staff innovativeness has been conceptualized as a multi-dimensional construct, which may include academic staff' attitudes towards the adoption of specific innovations, their general change-related values, their adoption of innovations, their internalization of adopted innovations, and their continual participation in change-related professional activities (Mcgeown, 2006).

Walley et al, (2017), Yi et al, (2006) has pointed out that the propensity to innovate has been referred to as innovativeness, innovative predisposition, innate innovativeness, and personal innovativeness (Agarwal and Prasad, 1998; Lin, 2006). Wally et al (2017), further identified five dimensions to a manager's Personal Innovativeness: Leadership, Team, Communication, Risk, and Reward. These five dimensions seem entirely appropriate and thus provide valuable insight for managers. Congruent with the argument of Agarwal and Prasad (1998), personal innovativeness is a construct that is important to the study of individual behavior with a longstanding tradition in innovation diffusion research. De Jong, den Hartog (2007) and Vincent et al, (2017), on the other hand defined employee innovativeness as the generation and implementation of significant new ideas, products and processes which are not assigned to task. Employee innovativeness can thus, be examined throughout the innovation process, from initial idea generation to product development, and eventually to product commercialization, or the adoption of new processes or structures in the organization. These studies demonstrate the need for universities to develop strong organizational culture that support innovativeness of academic staff.

Trot (2012) argued that innovativeness is reflected in individual's defined problems, having ideas and performing creative linkages and associations that lead to inventions and innovations within organizations. In addition, individuals in the role of managers decide what activities should be undertaken, the amount of resources to be deployed and how they should be carried out. This calls for university managers to strengthen organizational culture that support individual initiatives that culminate into employee innovativeness.

Employee innovativeness has been operationalized in various ways. Some have operationalized it in terms of a personality characteristic (Hurt et al., 1977) or an output. Others have taken a behavioral perspective (Janssen, 2000) and have measured employee innovativeness in terms of self-reported data (e.g. Bharadwaj \& Menon 2000, Ramamoorthy et al. 2005), some through manager evaluations (e.g. Thamhain 2003, Miron et al. 2004), some as new products (e.g. Damanpour 2006), some as new processes (Baer and Frese, 2003) and some 
as patent applications (Kivimäki, Länsisalmi, Elovainio, Heikkilä, Lindström, Harisalo, Sipilä \& Puolimatka 2000). In this paper, employee innovativeness is operationalized in terms of engagement in activities related to the innovation process, i.e. opportunity exploration, idea generation, idea promotion and idea implementation, with the aim of producing innovations (Ramamoorthy, Flood, Slattery \& Sardessai 2005). Innovations connected to the implementation or adoption of novel ideas can in turn be categorized as either technological (changes in products, services, production, processes) or administrative (changes in activities, social processes, structures), and as either radical or incremental, depending on the extent of their influence for existing products or processes (Damanpour, 2006). Most of the recent empirical research on employee innovativeness has, however, adopted a micro-level approach and focused on assessing what contributes to an employee's tendency to generate innovative ideas that eventually lead to innovations (Anderson et al. 2004). On the whole, it is the organization that provides the context for employee creativity and innovativeness, which in turn is at the root of every innovation - whether measured at individual, team or organizational level (Amabile et al. 1996, Anderson et al. 2004, Woodman et al. 1993).

Parzefall, Marjo-Riitta, Seeck, Hannele and Leppänen, Anneli (2008) summarized and discussed factors that influence employee innovativeness in organizations at different levels as; individual, job, team and organizational. They are said to influence innovative behavior, sometimes independently, but most often in interaction (Woodman, Sawyer \& Griffin 1993, Anderson, Dreu \& Nijstad 2004, Shalley \& Gilson, 2004).

Routine cultural resistance to innovativeness may arise from entrenched practices that inhibit people from looking beyond their own duties and ways of how things have always been done, as well as from stress associated with change and uncertainty. Similarly, interdepartmental competition for budgets and competences may result in disharmony, hampering the co-operation necessary for innovativeness (Van der Panne et al. 2003). Therefore, resistance to innovation does not only lie in factors external to the organization that are perceived as anti-innovative, but also in the ways that organizational members are confronted by organizational obstacles, and in their capacity to imagine and create a pro-innovative form of the organization (Salaman \& Storey 2002).

Besides, research has consistently shown that lack of routine is positively associated with innovativeness (Amabile \& Gryskiewicz 1999; Van der Vegt \& Janssen 2003). Specifically, when the job is intricate and demanding, employees are more likely to constantly focus their attention and effort on the job, and to consider various alternatives when looking for solutions (Shalley \& Gilson 2004).

Innovativeness inherently involves risks (Janssen, van de Vliert \& West 2004), and consequently, creative and innovative individuals have to be willing to try and accept the possibility of failing. However, environment and psychosocial safety at the workplace influence risk-taking; an employee's inclination towards risk is also an important factor: that explains why some people are naturally more averse to taking risks than others ( $\mathrm{Ng} \& \mathrm{Van}$ Dyke, 2001).

There are job-related factors that cover the contextual characteristics of the everyday work that impact on employee's innovativeness. Specific jobs and tasks play a significant role in influencing whether the employee engages in innovative work behavior, partially through motivating employees (Ford, 2000). That is, the way in which jobs are structured contributes to an employee's motivation, and thereby to their innovative behaviors. Research has repeatedly highlighted the importance of intrinsic motivation in creative work (Jung, 2001). Similarly, innovativeness requires a certain level of internal force that pushes the individual to persevere in the face of challenges in innovative work (Shalley \& Gilson 2004). Moreover, it is this internal force that keeps the person going even when the challenges are successfully overcome: it is question of positive tension, perseverance and desire to excel. Scott and Bruce (1994) have tested how the quality of the working relationships between individuals and their work groups affected innovative behavior. They found that in conditions of high team-member exchange, individuals have additional resources available to them in the form of idea sharing and feedback.

Imran, (2016) noted that there is effect of communication efficacy, communication climate (Arif, Zubair, \& Manzoor, 2012; Kohler, et al. 2010), mentoring (De Jong \& Den Hartog, 2007; Khan, Aslam, \& Riaz, 2012; Yidong \& Xinxin, 2012), networking (Jaskyte \& Kisieliene, 2006) on employees innovative work behavior. They placed these communication factors as the integrated factors for individual innovativeness at the workplace. Thus ,aligning institutional policies to foster innovativeness of academic staff has been found essential. Innovativeness of each faculty member is a crucial factor in teaching, research and community outreach. However, gaining real improvements can be achieved more rapidly and more cost-effectively if approached as a collective effort that is underpinned by well-aligned institutional policies. Inter-linkages between areas (disciplines, fields) and processes (lecturing, instructing, counseling etc.) are characteristics of organizational culture that can enhance innovativeness of academic staff. But stratified policies or department-wide or individual initiatives can prevent such synergies from emerging. For instance, a career development policy that emphasizes scientific publication may undermine institutional attempts to reward commitment to innovative teaching.

Innovativeness, or the tendency to create, share, and implement new ideas, is critical in driving success at 
both individual and organizational levels (Imran, 2016). Incidentally, individuals within the organizations are the key players in the implementation of innovative behavior at workplace. At the core of innovation lies creative ideas, and it is the employees, alone or in groups, who will generate, promote, discuss, modify, and realize these ideas (Scott \& Bruce, 1994). It is not surprising, therefore, that innovative employees are becoming the main commodity of contemporary organizations (Huhtala \& Parzefall, 2007), and therefore, the recruitment and development of such employees have been one of the main goals of any organization. However, although many types of research have been conducted on innovative behavior, there is a paucity of studies focusing on understanding the process that leads to it, thus, the current paper informs this gap.

\section{Conceptual framework}

Historically, individual innovativeness was addressed by tracing the observable behavior of individuals to see, for instance, if they have adopted or generated specific set of innovations (Goldsmith \& Foxall, 2003). Such approach was mainly referred to in the literature as innovative work behavior (Janssen, 2000). Hofstede's organizational cultural model highlighted the idea that organizational culture can initiate innovative ideas. Later, De Jong and den Hartog (2010) came up with an advanced Innovative Work Behavior (IWB) model. The model indicated four indices of innovativeness employee innovativeness, namely; Opportunity Exploration, Idea Generation, Championing and Application that manifest employee innovativeness. there were to act as the building blocks of innovativeness reflected in new and better products, services and work processes. Opportunity exploration and idea generation seemed to be enhanced by directly stimulating and probing employees to generate ideas (intellectual stimulation), supporting open and transparent communication processes, creating avenues for knowledge sharing and diffusion, and assigning challenging tasks to employees. As some academic staff have better opportunities for opportunity exploration and idea generation than others( for instance, Deans and Heads of Departments) who often meet external parties, leaders cannot reasonably expect a similar contribution to innovation from each of their academic staff.

\subsection{Opportunity Exploration}

This construct measures the urge to discover and to identify something new, look for ways to improve current products, services, creative problem solving processes (Basadur, 2004). According to De Jong and den Hartog (2010) opportunity exploitation manifests through construction of new ways to address needs, development of concept, ideas, processes, new products, services or processes, and improvements in work processes, or generally, provision of solutions to identified problems.

\subsection{Idea Generation}

Many studies focus mainly on the creative or idea generation stage of innovation (Mumford, 2000; McAdam and McClelland, 2002). Opportunities for idea generation and opportunity exploration also seem to be enhanced by directly stimulating and probing employees to generate ideas (intellectual stimulation), supporting open and clear communication processes, creating avenues for knowledge sharing and diffusion, and assigning challenging tasks to employees (Jeroen and De Jong,2010). Idea generation measures the degree of opportunity exploitation through building new ways of addressing needs, development of concept, ideas, processes, new products, services or processes, and improvements in current work processes, or in general terms, solutions to identified problems (Amabile, 1996).

\subsection{Idea Championing}

This stage of the IWB process is not always completed and as it may be restrained by a number of factors. Idea championing index measures the desire to sell, finding support and building coalition. It brings self- appreciation; a new legacy is created as a new idea is successfully championed; it attracts attention from other people; helps in mobilization of resources for implementation; an opportunity to compare ideas and chose the most efficient; helps presentation of the idea for others to comment; one learns a lot when one's idea is championed; new ideas need support to come to reality; championing helps in presentation for others to comment; through idea championing, one takes the challenge to lead the journey to implementation.

\subsection{Idea implementation}

This constitutes innovativeness as part of regular work process. In the implementation phase employees can play a valuable role in the innovation process by demonstrating application-oriented behavior. For example, employees with a strong personal commitment to a particular idea may be able to convince others of its value. 
Figure 4.1 below shows the conceptual framework of the relationship between organizational culture and employee innovativeness.

Organizational culture

\begin{tabular}{|c|c|}
\hline $\begin{array}{c}\text { Uncertainty Acceptance: } \\
\text { Creates Ease, Low Stress, Tolerance of } \\
\text { deviant Behavior }\end{array}$ \\
\hline $\begin{array}{c}\text { Low Power Distance: } \\
\text { Consultative \& Collaborative }\end{array}$ & $\begin{array}{c}\text { Opportunity Exploration } \\
\text { Look for opportunities to improve }\end{array}$ \\
Idea Generation \\
Search for new work methods \\
Idea Championing \\
Build coalition
\end{tabular}

Source: Primary Source

Three research objectives guided this paper namely; first, to assess the influence of uncertainty acceptance on the innovativeness of academic staff; second, to identify the influence of power distance on innovativeness of academic staff and third, to establish the impact of collectivism culture on innovativeness of academic staff.

\section{Organizational culture as antecedents to Innovativeness of academic staff.}

5.1 Uncertainty acceptance as predictor of innovativeness of academic staff.

Uncertainty acceptance culture as suggested by Hofstede (2001) refers to a culture that creates ease, lowers stress and creates low anxiety. Hofstede assumed that an academic staff working in an environment where uncertainty is accepted experiences low stress, feels at ease and executes his responsibilities with low anxiety. It measures employees' attempts to deal with uncertainty and ambiguity through tolerance of ambiguity and keeping stress levels low. Such academic staff tolerates ambiguities of new ideas. This type of culture is a determining factor for intention to innovate due to lower stress, collaborative and tolerance of deviant behavior. Uncertainty acceptance (UA) measures employees' attempts to deal with vagueness and ambiguity through formalization, regulation and tolerance.

Uncertainty Acceptance deals with the extent to which a social system rejects unstructured and ambiguous situations. It measures employees' attempts to deal with uncertainty through tolerance of ambiguity and keeping stress levels low (Nana, 2013). Nana explained that Uncertainty Acceptance is the extent to which the members of a culture feel threatened by ambiguous or unknown situations and have created beliefs and institutions that try to avoid these. In a collectivist culture, individuals belong to in-groups. The employees act according to the interests of this in-group, which may not always match with his or her individual interests. Risks could be reduced when hiring someone already known. People from high Uncertainty Acceptance prefer certainty and predictability rather than ambiguous and risky situation (Hofstede, 1990). In low uncertainty acceptance, people are less concerned about unpredictability. They do not like too many rules which restrict their freedom. In the end, there is more risk-taking.

Uncertainty avoidance is the extent to which members feel threatened by ambiguous and uncertain situations that are stressful. This necessitates the need for rules, norms, laws and informal guidelines in place to help manage uncertainties (Hofstede, 2011). Jones, (2007) stated that Uncertainty Avoidance is the extent to which people are threatened by a lack of structure or by uncertain events. Hence, people with low Uncertainty Acceptance will require structure and order with clear rules and guidelines while people with high UA will strive for security, and innovations may be resisted (Nana, 2013). In a strong uncertainty avoidance culture, people prefer rules, regulations, and the conservative legal order, and do not like adventure and innovation. In order to avoid risks, they prefer stable jobs, a secure life, avoidance of conflict, and have a lower tolerance for deviant persons and ideas. In contrast, in a week uncertainty avoidance culture, conflicts and competitions are acceptable. In summary, the propositions of Uncertainty Acceptance indicate the way in which people will deal with the future, whether they have inherent control, or whether events are beyond their control (fatalism).

\subsection{Power distance as a predictor of innovativeness of employee innovativeness}

Power distance is the measure of inequality among people. This implies that a society's measure of inequality 
might be approved by both leaders and followers (Wei et al., 2008, Bankole, 2017). Power distance refers to the degree of human difference in terms of status or social power which creates social hierarchy. Lans, et al (2015) observed that results for learning on the group level are significantly lower than the results for learning on the individual level. Nevertheless, teamwork is highly important for the interpretation and further developments of ideas. Therefore, academic staff group formation, interaction within and outside groups, and teamwork are more likely to support and facilitate to enhance employee innovativeness.

Lans, et al (2015), further argued that employees learning on the organizational level do not experience the organizational culture as innovative. Therefore, creating and stimulating an innovative culture (in which experimenting is facilitated) seems essential. Lans, et al (2015) concluded that a flat structure, autonomy, formal and informal learning contribute to feedback learning and innovativeness, these are concrete examples of how feedback learning and innovation can be fostered. Although it is acknowledged that a "one-size-fits-all" does not exist.

The power of knowledge is enhanced when knowledge is shared to bring innovative ideas products and processes (Nonaka \& Takeuchi, 1995), and new programs (Hislop, 2013). Academics being one of the pillars of HEIs, where knowledge is created and shared, they are expected to promote academics' knowledge sharing culture. However, the actual behavior of academics might remain inhibited by numerous issues, namely; the organizational cultural elements (Osama, Al-Kurdia, Ramzi El-Haddadehb and Tillal, 2020). Innovativeness concerns employees' perceptions that the organization highly regards creativity and innovation. In a climate of free flowing information, employees trust others and management promote innovativeness and affiliation. This builds trust between organizational members and management and can promote employee innovativeness (Osama, 2020).

\subsection{Collectivism as a predictor of employee innovativeness}

Hofstede and Bond (1984) defined collectivism as "a psychological tendency that places collective interests above individual interests". This suggests that encouraging collectivism could be an important objective, as it moderates the relationship between knowledge sharing and innovative behavior positively. Although a clear definition of collectivism is still debatable, research on the impact of collectivism on individual behavior has been growing rapidly. For example, Jiang et al. (2016) concluded that collectivism could influence employees' cognitive and behavioral tendencies and affect their behavioral outcomes, of which knowledge sharing and innovative behavior were two prominent outcomes. In a collectivist culture, individuals belong to in-groups. The employees act according to the interests of this in-group, which may not always match with his or her individual interests. Thus, risks could be reduced when hiring someone already known.

Pian, Jin and Li, (2019) examined the relationship between behavior-oriented knowledge sharing and innovative behavior and the moderating effects of collectivism. The results revealed that epistemic motivation stimulates individual-oriented knowledge while sharing and pro-social motivation stimulates organizationoriented knowledge sharing. In addition, collectivism was shown to positively moderate the relationship between behavior-oriented knowledge sharing and innovative behavior. Collectivism was as a result, regarded as a core construct in analyzing cultural effects on human relationship.

A university is seen as a platform for academics to share ideas and insights (Martin \& Marion, 2005).Through such platforms innovative ideas are generated and shared which ultimately enhance innovativeness of academic staff. Hofstede (2010) indicated that in collective cultures, the interest of a group or organization is valued more than the interest of an individual. In a collectivist culture, individuals belong to ingroups. The employees act according to the interests of this in-group, which may not always match with his or her individual interests.

Hassan, Ramli, Sumardi, Halif, Mazuin, Othman, Zainal, Aziz (2019) carried out a comprehensive review on impact of Employee Mindset on employee innovativeness that had been prominent among researchers and educators over the decades. They portrayed Employees Mindset as comprising of four subsets; Cosmopolitanism, Cognitive complexity, entrepreneurial mindset, Boundary spanning and adaptability. Though the components reviewed were on employee innovativeness generally, the context was not on higher education.

Muceldili,Turan and Erdil (2013) carried out and empirical study to analyze how authentic leadership (AL) predicts employee innovativeness both directly and indirectly; through mediating role of employees' creativity. A sample of 142 employees working in organizations operating in Turkey Marmara Region were surveyed to find out whether Authentic leaders may have an impact on innovation. The main findings were; AL has a positive relationship with employees' creativity; employees' creativity has a positive impact on innovativeness and AL has a positive relationship with innovativeness. They indicated that Authentic leadership may foster innovation more than traditional leadership styles via building confidence, creating hope, raising optimism and strengthening resilience. Additionally, authentic leadership may also have an effective role for enhancing innovation through relationship with followers. Although the model of Muceldili, Turan and Erdil (2013) reviewed impact of Authentic Leadership on employee innovativeness, they do not apply specifically to 
innovativeness of academic staff in a university context. Whereas innovativeness was measured by nine items (product, process and administrative) adopted from Jimenez and Valle (2011), a new study would measure innovativeness using Hofstede's organizational culture model.

\section{Conclusion.}

This paper reviewed literature on employee innovativeness focusing on conceptual and theoretical planes. The paper was divided into six sections. In section 1, the definition of employee innovativeness is given, emphasizing its nature as a multi-dimensional construct made up of the four perspectives; opportunity exploration, idea generation ,idea championing and idea implementation, pointing out its importance in discovering and identifying something new ways to improve current products, services, processes. This is because it facilitates in search for opportunities to improve, search for new work methods, build coalition and making innovation part of regular work process. In section two, an elaboration of the organizational culture model underpinning the study is give illustrating its capacity to enhance employee innovativeness. In the third section a conceptualization of employee innovativeness is done culminating into a framework illustrating the different dimensions of employee innovativeness. The empirical literature reviewed identified that most studies relating to employee innovativeness have been done outside Sub-Saharan Africa thus setting a challenge for future researchers to focus on Africa.

Conclusively, government needs to take serious action on developing academic staff toward their innovativeness. The need for them to become creative and innovative is very vital. Academic staff who recommend new ways of doing things to make it more effective, should be rewarded. Education and training in higher education can contribute to the promotion of innovativeness of academic staff. Hence, more training and relevant courses should be extended to academic staff to keep them knowledgeable of the latest technology.

University institutions are strongly pursuing excellence, requiring university management to provide an organizational culture that creates a supportive environment for organizational learning. This would enable the university to source knowledge from the minds of its members, through the formation of a common vision among employees to contribute to the establishment of the strategic changes that are required for innovativeness.

\section{Acknowledgements}

My gratitude goes to my supervisor, Associate Professor Jude Ssempebwa and my dear wife Ritah Hab'Imana for their academic and moral support. I appreciate all staff in Makerere University College of Education and External Studies (CEES) for the support rendered to me during my studies.

\section{References}

Agarwal, R., \& Prasad, J. (1998). A conceptual and operational definition of personal innovativeness in the domain of information technology. Information Systems Research, 9(2), 204-215.

Alkailani, M., \& Kumar, R. (2016). Impacting innovativeness: The role of interpersonal influences and cultural dimensions on consumer innovativeness. Journal of Strategic Innovation and Sustainability, 11(1).

Amabile, T.M. (1999), "A model of creativity and innovation in organizations", in Shaw, B.M. and Cummings, L.L. (Eds), Research in Organizational Behavior, Vol. 10, pp. 123-67.

Anderson, N., K. Potočnik, and J. Zhou. (2014) Innovation and creativity in organizations: A state-of-thescience review, prospective commentary, and guiding framework. Journal of Management 40 (5): 1297-333.

Arif, S., Zubair, A., \& Manzoor, Y. (2012). Innovative Work Behavior and Communication Climate among Employees of Advertising Agencies. Quaid-i-Azam University, Islamabad.

Baer, M. and Frese, M. (2003) Innovation is not enough: climates for initiative and psychological safety, process innovations, and firm performance. Journal of Organizational Behavior, 24(1), 45-69.

Bankole F,O., (2017). The effects of cultural dimension on ICT innovation: Empirical analysis of mobile phone services. Telematics and Informatics. Volume 34, Issue 2, May, Pages 490-505.

Basadur, (2004), Leading others to think innovatively together: Creative leadership. The Leadership Quarterly. Volume 15, Issue 1, February 2004, Pages 103-121.

Basu and Green(1997) Leader-Member Exchange and Transformational Leadership. An Empirical Examination of Innovative Behavior in Leader -Members Dyads. Journal of Applied Psychology, 1997, 27, 6. PP 477499.

Damanpour, F., Schneider, M. (2006). Phases of the adoption of innovation in organizations: Effects of environment, organization and top managers. British Journal of Management, 17(3): 215-236.

De Jong, J. P., \& Den Hartog, D. N. (2007). How leaders influence employees' innovative behaviour. European Journal of Innovation Management, 10(1), 41-64.

De Jong, J., \& Den Hartog, D. (2010). Measuring innovative work behavior, Creativity and Innovation Management, 19(1), 23-36.

Engelen, A. (2010). "Entrepreneurial Orientation As a Function of National Cultural Variations in Two 
Countries," Journal of International Management 16(4), 354-368.

Farr, J. and Ford, C. (1990) Individual Innovation. In West, M. and Farr, J. (eds.), Managing Innovation. Sage, London.

Goldsmith, E., \& Foxal, G. (2003). The Measurement of Innovativeness. In L. V. Shavinina (Ed.), The International Handbook of Innovation. Oxford: Elsevier Science. pp. 321-8.

Hasanefendic, S., Birkholz, J.M., Horta, H. \& van der Sijde, P. (2017). Individuals in action: bringing about innovation in higher education. European Journal of Higher Education, 7 (2), 101119.doi.org/10.1080/21568235.2017.1296367.

Hassan, Ramli , Sumardi, Halif, Mazuin, Othman, Zainal, Aziz (2019) The Effects of Employee Mindset on Employee Innovativeness: A Comparative Study Between Professional and Non-Professional Groups among Government Staff in Putrajaya, Malaysis.

Heslin, P. A. (2010). Mindsets and employee engagement: Theoretical linkages and practical interventions. In S. L. Albrecht (Ed.), Handbook of employee engagement: Perspectives, issues, research and practice. (pp. 218-226). Edward Elgar.

Hislop, D. (2013). Knowledge management in organizations (3rd ed.). Oxford: Oxford University Press.

Hofstede, G, J., \& Michael Minkov (2010). Cultures and Organizations. Details

Hofstede, G. (2011). Dimensionalizing cultures: The Hofstede model in context. Online readings in psychology and culture, 2(1), 8 .

Hofstede, G., Neuijen, B., Ohayv, D, D., and Sande, G,. (1990). Measuring Organizational Cultures: A Qualitative and Quantitative Study Across Twenty Cases. Administrative Science Quarterly, Vol. 35, No. 2 (Jun., 1990), pp. 286-316.

Huhtala, H., \& Parzefall, M. R. (2007). A review of employee well-being and innovativeness:An opportunity for a mutual benefit. Creativity and Innovation Management, 16(3), 299-306.

Imran, A. I. (2016). Communication Factors Influencing Academicians' Innovative Working Behavior and Its Impact on Their Career Advancement. Jurnal Ilmiah LISKI (Lingkar Studi Komunikasi), 2(1), 29-51.

Janssen O, E, van de vliert1 and M, West (2004) The bright and dark sides of individual and group innovation: a Special Issue introduction. Journal of Organizational. DOI: 10.1002/job.242.

Jaskyte, K and Kisieliene. A. (2006) Organizational innovation: A comparison of nonprofit human-service organizations in Lithuania and the United States. International Social Work March, 49(2):165-176.

Jenseen Van de (2004) The bright and dark sides of individual and group innovation: a Special Issue introduction. Journal of Organizational Behavior. 25, 129-145.

Jeroen P.J. de Jong, Deanne N. Den Hartog, (2007) "How leaders influence employees' innovative behaviour". European Journal of Innovation Management, Vol. 10 Issue: 1, pp.41-64.

Jones, G. and Davis, H. (2000), "National culture and innovation: implications for locating global R\&D operations". Management International Review, Vol. 40 No. 1, pp. 11- 20.

Khan, M, Jand Aslam, N and Riaz(2012) Leadership Styles as Predictors of Innovative Work Behavior. Pakistan Journal of Social and Clinical Psychology, Vol. 9, No. 2, 17-22.

Kohler, T., C, Janßen, SC Plath, JP Reese, J Lay ,(2010) Communication, social capital and workplace health management as determinants of the innovative climate in German banks.

Lans, T., Biemans, H. J. A., \& Baggen, Y. (2015). High levels of individual and feed forward learning foster employee-driven entrepreneurship and innovativeness: Policy Brief, proceedings of LL Light'in'Europe research project. LL Light in'Europe.

Lin ,JK., (2006) Serving Web 2.0 with SOA: Providing the technology for innovation and specialization. IEEE International Conference on e-Business.

Mcgeown,V,(2006). Dimensions of Teacher Innovativeness. British Educational Research Journal. Volume 6, 1980 - Issue 2. doi.org/10.1080/0141192800060204

Muceldili, B. Turaran, H. and Erdil, O. (2013) The Influence of Authentic Leadership on Creativity and Innovativeness. Procedia - Social and Behavioral Sciences 99, $673-681$

Nana. Y, O(2013) Towards African Work Orientations: Guide from Hofstede's Cultural Dimensions. European Journal of Business and Management www.iiste.org Vol.5, No.20.

$\mathrm{Ng}, \mathrm{K}$. Y. and Van Dy ne, L. (2001) Individualism-Collectivism as a boundary for the effectiveness of minority influence in decision-making. Organizational Behaviour and Human Decision Processes, 84: 198-225.

Nieves, J., Quintana, A., \& Osorio, J. (2014). Knowledge-based resources and innovation in the hotel industry. International Journal of Hospitality Management, 38, 65-73.

Nonaka, I., \& Takeuchi, H. (1995). The knowledge creating company. Oxford: Oxford University Press.

Omerzel, D. G., (2016). The Impact of Entrepreneurial Characteristics and Organizational Culture on Innovativeness in Tourism Firms. Managing Global Transitions. International Research Journal. Vol. 14• No 1 Spring International Research Journal.

Osama F. Al-Kurdia, Ramzi El-Haddadehb,, Tillal Eldabib(2020). The role of organizational climate in 
managing knowledge sharing among academics in higher education. International Journal of Information Management. Vol. 50, 217-227.

Parzefall, M.-R., Seeck, H., \& Leppänen, A. (2008). Employee innovativeness in organizations: a review of the antecedents. Finnish Journal of Business Economics, 2(08), 165-182.

Ramamoorthy, N., Flood, P. C., Slattery, T., \& Sardessai, R. (2005). Determinants of innovative work behavior: Development and test of an integrated model. Creativity and Innovation Management, 14: 142-150.

Scott, S.G. and Bruce, R.A. (1994) Determinants of Innovative Behavior: A Path Model of Individual Innovation in the Workplace. Academy of Management Journal, 38, 1442-65.

Serdyukov (2017) Innovation in education: what works, what doesn't, and what to do about it? Journal of Research in Innovative Teaching \& Learning .Emerald.com.

Shalley, C.E. and Gilson, L.L. (2004) What leaders need to know: A review of social and contextual factors that can foster or hinder creativity. Leadership Quarterly, 15(1), 33-53.

Thamhain, H.J. (2003) Managing innovative R\&D teams. $R$ \& D Management. 33(3), 297-311.

Trott, P. (2012) Innovation Management, 5th edition, Financial Times Prentice-Hall, Pearson, Harlow, Essex.

Van Yperen, N. W., and M. Hagedoorn. (2003). Do high job demands increase intrinsic motivation or fatigue or both? The role of job control and social support. Academy of Management Journal 46 (3): 339-48.

Vincent, E. A. (2017). Examining the Experiences of Innovative Counselor Educators: A Grounded Theory Approach.

Walley, K., Goodall, S., Humphries, A., Huntington, J., White, D. and Asson, T. (2017). Key Dimensions of Personal Innovativeness. International Journal of Business and Innovation, 12(2).

Wei, J., Stankosky, M., Calabrese, F., Lu, L., (2008). A framework for studying the impact of national culture on knowledge sharing motivation in virtual teams. J. Inf. Knowl. Manage. Syst. 38 (2), 221-231.

Yidong \& XinXin (2013) How ethical leadership influence employees' innovative work behavior: A perspective of intrinsic motivation - Journal of business ethics, Springer.

Yuan \& Woodman (2010) Innovative behavior in the workplace: The role of performance and image outcome expectations. Academy of management journal, 2010 - journals.aom.org 